\title{
Towards the Business Federation in Top Management Consulting in Europe: The Role of Co-creation
}

\author{
Carsten Martin Syvertsen \\ Oestfold University College \\ 1757 Halden, Norway \\ Tel: 47-6921-5000Ｅ-mail: carsten.syvertsen@hiof.no
}

Received: December 12, 2011

Accepted: December 28, 2011

Published: March 1, 2012

doi:10.5539/ibr.v5n3p16

URL: http://dx.doi.org/10.5539/ibr.v5n3p16

\begin{abstract}
We present the business federation as a new organizational form. We illustrate how management consulting firms can achieve economic growth through operating locally within an international network. We use management consulting firms operating in Western Europe as our empirical setting. Within the business federation local offices gain access to resources through an extreme form of delegation as it is not top management that delegates to local offices but rather local units that give top management the permission to handle certain tasks because it is most efficient to do so. Using questionnaire as instrument, the article illustrates how the business federation is supposed to function through the use of five organizational design parameters. The research shows a support for the claim that firms that operate close to principles of the business federation achieve a stronger economic growth than other firms operating further away from the federation, using profits per partner as the criteria. Firms that started out from strategy consulting achieve a higher growth rate than other firms. The research contradicts claims found in the academic literature as alternatives to the partnership model supports economic growth.
\end{abstract}

Keywords: New organizational forms, The business federation, Co-creation, Management consulting firms, Europe

\section{Towards Co-creation in New Organizational Forms in Europe}

The first couple of decades after 1945 were the golden years of economic growth where companies where rewarded for introducing, developing and sustaining strong organizational hierarchies and strict work roles. Today the situation has changed dramatically. Markets have become highly competitive and turbulent, and are constantly changing. Markets conditions move from being simple to complex, from stable to dynamic, and from being tame to being hostile (Neu \& Brown, 2005). Economic turbulence linked to accelerating internationalization, continuous improvements of technologies and deregulation of markets have profound impacts on firm's competition. As new business regimes emerge, managers are realizing that the basis of competitive advantage is found in the customer base. Value and meaning are created together with customers and other stakeholders, through a process called co-creation among business managers and academics.

Economists and environmental analysts ascribe these changes to transformations of the economic infrastructure. A metamorphosis leads to a replacement of manufacturing resources with knowledge as a driving force of economic growth. Capital, labor and property, in other words the economist's traditional factors of production, are still important, but become less crucial as sources of value creation (Leonard-Barton, 1995; Nonaka \& Takeuchi, 1995; Grant, 1996a; Grant, 1996b). Knowledge can be regarded as operant resources that often are dynamic, invisible and intangible (i.e. Constantin \& Lusch, 1994; Vargo \& Lusch, 2004). Increasingly, both practitioners and academics are shifting toward viewing customers as co-creators. Among academics, Normann and Ramirez (1993, p. 69) state that "the key to creating value is to coproduce offerings that mobilize resources". Prahalad and Ramaswamy (2000) argue for co-creating customer involvement as markets have become a venue of proactive customer involvement. Lusch et al. (1992) provide a general model to explain how much the customer will contribute to the co-creation process. Oliver et al. (1998) extend the idea of co-creation by introducing the concept "real-time" marketing, which integrates mass customization and relationship marketing in order to meet customers changing needs.

Closely linked to the coproduction process is the service-centered view of marketing, which can be regarded as both customer-centric (Steth et al., 2000) and market-driven (Day, 1999; Day, 1994). This means more than simply being consumer-oriented; it means being adaptive to customers' individual and dynamic needs. A service-centered dominant logic implies that value is defined by and be co-created with the customer rather than embedded in outputs. 
Haeckel (1999) observes successful firms moving from practicing a "make-and-sell" strategy to a "sense-and-respond" strategy using the market place as a learning arena. Thus, a market-oriented and a learning organization are compatible with the service-centered model (Slater \& Narver, 1995).

The emerging service-centered dominant logic is also compatible with emerging theories of the firm (Teece et al., 1997) stressing that economic uncertainty calls for a more dynamic approaches in analyzing, formulating and implementing strategic possibilities. For this reason we use an approach derived from evolutionary economics illustrating that the use of dynamic competences is dependent on routines (Nelson \& Winter, 1982).

\section{Towards the Business Federation in Management Consulting Firms}

Increased turbulence, increased change and knowledge requirements have led to increased complexity, both internally and externally in organizations. As a consequence, co-creation becomes more important. By using co creation as a tool it is possible for firms to identify and explore business opportunities by taking an entrepreneurial strategic posture, building on strong performance incentives. Being entrepreneurial allows a firm to be responsive to lucrative market opportunities. An entrepreneurial strategic posture can also give advantages by responding quickly to business opportunities at the same time as firms can be able to repress business threats. Being agile evolves staying nimble and flexible, open to new evidence, ready to reassess past choices and change direction as business opportunities are explored and exploited.

Handy $(1992,1994)$ extends the nature of contradictions that managers face to issues related to power and control. He adds that a major challenge for modern businesses is to try to achieve the advantages of large firms as well as small ones. Handy is of the opinion that the federalist concept, applied to the business context, is particularly appropriate to deal with managerial contradictions. A company that seeks growth can emphasize an organizational model that tries to solve the dilemma of operating locally within an international network. This dilemma should be in accordance with the times we live in. We wish to be a part of a strong entity at the same time as we prefer a high degree of autonomy in our professional lives. Within the business federation it is not the top management that delegates to local units but rather local units that give top management the permission to handle certain tasks because they are handled more efficient at the top, for example when introducing corporate support services. The center does not direct or control, but rather advices, coordinates and influences, being well aware that initiatives generally come from local levels (Handy, 1992; Handy, 1994).

\section{Introduction of a Building Block Systemin Order to Describe the Business Federation}

A number of management thinkers and researchers advocate a process of renewal of corporations which inevitably will lead them to behave more in accordance with federalist principles (Simon et al., 1950; Drucker, 1954; March \& Simon, 1958; Provan, 1983; Bartlett \& Ghoshal, 1988; Bartlett \& Ghoshal, 1995; Handy 1992; Handy, 1994). However, these authors only provide a partial understanding of the importance of federalist behavior. We describe federalist behavior though the use of a building block system consisting of autonomy at local levels, the extent to which local offices share resources, ownership of resources at local levels, lack of hierarchical control of local units, and how corporate services can be used. The building block system represents a guide for how to hold international management consulting firms together, and illustrates how co-creation can be used in the sampled firms.

\subsection{Autonomy}

It is often assumed that autonomy can promote entrepreneurial activities. This argument can also be used in studies of the business federation since autonomy can influence entrepreneurial processes. The relationship between autonomy and performance is assumed to be positive since local levels may serve clients in a better way than the corporate level can. Our findings support this argument.

\subsection{Resource Sharing / Interdependence}

Management consulting firms face challenges in providing local offices with access to limited resources without duplicating costs. This requires specialization and coordinated efforts among local offices, in accordance with marketing thinking as individuals and companies are constantly moving toward more specific specialties (Shugan, 1994). A positive relationship between resource sharing and economic performance can be expected. Our research supports this argument.

\section{3 "Ownership"}

Within management consulting firms it is generally assumed that partnership models, with the use of up-or-out promotion policies, can make sense since a firm's reputation among clients and other market intermediates are closely related to the perceived quality of the partners. Our findings do not support such an argument as the 
partnership model might not function as expected since it may involve a loss of considerable firm-specific knowledge.

\subsection{Control Mechanisms}

Social means of control, consisting of ideology, culture and sanctions, can regulate behaviors at local levels within the business federation. By ideology we mean integrated set of beliefs that unite a firm so that members are ensured basic knowledge on how a firm is supposed to work. Culture can be regarded as cognitive mindsets, manifested through behaviors and language. Sanctions can involve that group members punish colleagues who violate goals, norms and values, ranging from gossips and rumors to ostracism and sabotage (Ferlie and Pettigrew, 1996). Social means of control are supposed to have a positive effect on performance. Our findings support this argument.

\subsection{Corporate Services / Boosting Units}

Through the use of corporate services management consulting firms can leverage cumulative experiences found in the client base. Local offices can concentrate on promoting entrepreneurial processes. Our findings are in accordance with this argument.

\section{Top Management Consulting Firms Used as the Empirical Setting}

The top management consulting industry represents the empirical setting of the research. Given the nature of the consulting industry, it maybe expected that consulting services provide an adequate setting for the adoption of changes in design parameters which can move firms towards the business federation. The business federation can balance the need for coordination and local autonomy. Therefore, insights derived from the business federation can be used to explain phenomenon of specific configuration choices in strategy consulting firms.

The sample is drawn from a population of local offices within strategic practices being located in eleven West European countries. All leading international consulting firms decided to participate in the research. The research is restricted to internal configurations of consulting firms, with an interest in the relationship between local offices and the head quarter. Only management consulting firms with offices in several countries are included in the sample.

The unit of analysis is local offices within management consulting firms with international operations. Within the local offices we limit the analysis to top management consulting. Such consulting is conceived to include formulation and implementation advice, as well as related areas such as restructuring, and mergers and acquisitions. The research focuses on a relatively homogeneous group of services enhancing the likelihood of correct interpretation of common categories. Differences in office attributes have been allowed for, such as the diversity of consulting services offered, founding year of the firm, size of offices and the ownership structure.

The target population is made up of European management consulting firms, specializing in strategy. A database of local managing directors was compiled, including the information provided by the firms and field directories. The population consists of 185 national offices. A total of 65 local offices responded to the survey, which represents a $35 \%$ response rate. Eight top consulting firms provided three or more responses from different countries. Four responses were dropped from the analysis because they could not be correctly defined as strategy consulting practices.

Data collection posed major challenges given the small population size, the nature of information requested, and the industry's norms regarding secrecy. In order to maximize the response rate the questionnaire was extensively pre-tested. A preliminary questionnaire was returned from nineteen local offices in Norway and Spain at the end of 1997. Meetings with senior consultants in Spain helped to refine the questionnaire before being used in a larger European survey.

A survey, directed towards the selected 185 local offices, generated 38 responses in March 1998. A duplicate copy of the survey was sent by fax in November 1998 providing 27 additional responses. We report the results received until the middle of December 1998. The questionnaire made it explicitly clear that the relevant situation was the one prevailing in January 1998. All firms were international in their scope of activities, yet with different degrees. All firms offered various services in addition to top management advice. Eight firms had top management services as their primary area of activity.

The questionnaire is divided into 14 parts. Three sections are devoted to the measurement of autonomy of local offices, two to control of the office by the head-office, one to the existence and rules governing the use of support services, one to ownership of local resources, and four to interdependence and resource sharing between local offices. All explanatory variables were coded so that higher values imply closeness to the federation and lower values correspond to deviation from federalist behavior. Two sections measure performance at the office level, 
another one tries to capture the strategy focus, and a final section, contains basic demographics of a given local office.

\subsection{Performance Measures}

Given the exploratory nature of this study, it was decided not to use the full set of performance indicators included in the questionnaire. "Profits per partner" was selected in favor of ranks on "total revenues" and "revenues per consultant" since the former is a more comprehensive measure of performance capturing the aspects of the relationship between the partners and the firm (for example, the institutional configuration of power and ownership of the firm), which the other indexes would not cover.

\subsection{Control Variables}

We measured the focus of the strategy practice within in its attempt to add value to customers. We also asked about demographics of the strategy practice, covering aspects such as age and size. As explanatory variables the following was chosen in order to describe federalist behavior: autonomy of local offices, control mechanisms over local offices, supply services, ownership over local resource, and resource sharing/independence between local offices.

\subsection{Autonomy of the Local Office}

We presented three types of questions, one related to the degree of flexibility in customizing services to specific clients, one to the nature of authority of the local office, and one to the possibilities to decide on issues, for example when entering into an alliance at local levels. We ran an exploratory factor analysis as a variable reduction technique. Four meaningful factors explained $73.1 \%$ of the variance, based on 56 observations. The factors, which emerged after rotation, can be described as:

Factor $1(22.98 \%)$. Autonomy in setting the institutional configuration of the company in the country of the local office; entering into an alliance (0.859), merging at a national level (0.868) and promotion to a partnership position (0.779).

Factor $2(12.60 \%)$. Autonomy in defining the business strategy of the office; expanding into new segments $(0.854)$ and changing business strategy $(0.633)$.

Factor $3(13.36 \%)$. Autonomy in decisions involving the use of local resources; local skills used by foreign offices $(0.708)$ and following a client abroad (0.821).

Factor 4 (24.15\%). Autonomy in serving customers (operational autonomy); standard client fees (0.875), customizing services $(0.712)$ and how to serve clients $(0.779)$.

\subsection{Resource Sharing / Independence}

Four sections were devoted to focus on resource sharing and independence. In the first section we tried to measure the extent to which local offices use formal means (systems, procedures and politics) designed to share resources with other offices. In addition, we used informal means as guidelines for sharing resources. We also asked for the percentage of time consultants used in other local offices in order to analyze interdependence between local offices more closely.

Factor analysis generated three common factors, with all twelve original variables included explaining $68.93 \%$ of the variance. Higher degrees of independence and more use of formal means of resource sharing are consistent with closeness to the business federation. A priori, we associated more intense use of informal means of resource sharing to be in accordance with federalist principles, however without a theoretical argument supporting this link.

Factor $1(25.28 \%)$. We focus at formal means of resource sharing, mainly sharing of information; formal means/serving clients $(0.876)$, informal means of serving clients $(0.683)$ and formal means of managing a local office (0.761).

Factor 2 (21.82\%). Use of informal means of resource sharing; informal means/industry experience (0.86), informal/functional experience (0.780) and informal information on clients (0.745).

Factor $3(21.93 \%)$. Interdependence and use of formal means of sharing expertise; working days devoted to other offices $(0.812)$, working days used at other offices $(0.774)$, formal means/industry experience $(0.725)$ and formal means/functional expertise (0.745).

\subsection{Ownership over Local Asset}

A main characteristic of the business federation is that power belongs to the lowest level in the hierarchy, in accordance with principles of the co-creation literature (i.e. Day, 1994). We associated higher values with local 
ownership would imply closeness to the federation. Two factors explained $80 \%$ of the variance, based on 55 observations.

Factor 1 (40.84\%). Local ownership of economic resources generated at the local level; cash flow (0.880 \%) and cash available (0.895).

Factor 2 (39.54\%). Local ownership of intangible assets located at the local levels; professional skills (0.857) and the relationship with clients (0.890).

\subsection{Control over Local Units}

The measurement of control of local units was used in order to focus on the extent to which local units can deviate from standards set by head office. We also measured the extent to which head office regulate activities of the strategy practice within local offices. Factor analysis generated three common factors, with the inclusion of ten of the original fourteen items, explaining $74 \%$ of the variance. On the first and the third factors 56 observations were used, while 57 observations were used on factor two.

Factor 1 (32.7\%). The use of cultural control; shared values (0.876), goal accomplishments (0.824), management by objectives $(0.751)$, collective decision making (0.802) and internalized norms of conduct (0.706).

Factor $2(20.2 \%)^{*}$. Lack of operational control, that is, the extent to which local offices are free to deviate from standards set by head quarter; clients to serve $(0.867)$, setting client fees $(0.704)$, and composition of project teams (0.765).

Factor $3(21.0 \%)^{* *}$. Lack of bureaucratic control; job description on functions and activities $(0.976)$, and written rules and standard procedures $(0.982)$.

* The original scale was reversed in such a way that higher values indicate more freedom to deviate from standards.

** The original scale was also reversed so that higher values would indicate the non-existence of bureaucratic control since this was presumed to be associated with federated principles.

\subsection{Supply Services / Boosting Units}

Eight types of possible support services were listed. The respondents were asked to mark on items inquiring about whether the service is available, and, in the case the service was provided, whether the office was free to decide how to use it, and whether the office had to pay for such services. We counted the number of occasions each event occurred. These measures serve as a proxy to capture to what extent supply services existed and the rules governing their use.

Even though the computer suggested using one factor, we decided to use two since we anticipated two different components associated with the use of supply services. Two meaningful factors explained $90 \%$ of the variance, based on 54 observations. We measured both the number of services and the freedom for how to use them. The factors weighted equally. We decided to include the variables in the composition of each factor, with corresponding factor loadings.

Factor $1(45.19 \%)$. The existence of shared services operating with market rules/freedom to decide how to use and subject to an internal market for services; number of services to pay for $(0.957 \%)$ and number of services/freedom to use shared services $(0.645)$.

Factor $2(44.68 \%)$. The existence of support services not compulsory for local units; number of supply services available (0.958) and number of services/freedom to use them (0.633).

\section{Factor Analysis and Regression Analysis}

In accordance with the exploratory purpose of the research, we used a number of simple techniques in order to learn from data collected. We first ran an exploratory factor analysis (with Varimax rotation) to gain insights on the underlying interrelationships among original variables included in each design dimension.

\subsection{Rotated Factor Analysis as Inputs in a Regression Analysis}

To explain the effect of design choices associated with the business federation on performance we estimated a series of OLS regression models, using the results of rotated factor analysis, described in the former section, as inputs in the regression.

We compared and contrasted the results of regression under two different schemes of factor composition: first, when variables are included in the factor model with their respective factor loading, and on the other, when the principal components include only the factors giving meaning to the factors. The initial results were not very different, yet some regression coefficients were not stable across models due to interaction effects, not initially included in these 
comparison analysis. We chose to use the case where factors were formed including only the original variables which provided meaning to each factor.

\subsection{Findings and Interpretations}

BOOSTING F1 captures the existence of shared services where local offices are free to decide how to use such services. Market conditions regulate the relationships between local offices and support service units found centrally. On the other hand, the mere availability of more support services is not associated with performance, as the negative sign of BOOSTING F2 suggests. "Local ownership of economic resources generated" has not a clear effect on performance, with alternate signs and not significant slopes. On the contrary, "local ownership of intangible assets located at the local level" (OWNERSH F2) shows a negative main effect if we do not take into account interaction effects, yet it turns out to be high, positive and significant if we are able to remove some of the interrelationships with other factors. "The use of formal means of sharing information" has a positive effect on performance. However the level of significance is low. "The use of informal means of resource sharing across offices" has a consistent negative effect on performance.

The estimation of the models presented clearly suggests the existence of interaction effects and moderated causal relationships in addition to direct effects. The parameter of AutoF3*ControlF3 (2.07) implies that for every unit that "lack of bureaucratic control" increases, the slope of "autonomy over the use of local resources" on performance increases with two units. The coefficient 1.93 of AutoF3*ExpShINTP suggests that the slope of "autonomy over the use of local resources" on performance increases almost two units, giving a one unit increase in "interdependence and formal means of sharing knowledge". However, we would have expected that the lack of operational control coupled with benefiting from operational autonomy would permit an office to tailor-make products to specific needs of national markets, and therefore be positively related to performance. Consistent with the theoretical framework is the positive and consistent effect of internal use of corporate services/boosting units could be expected.

\section{Insert Table 1 Here}

"Local ownership of resources generated" has not a clear effect on performance, with alternate signs and non-significant slopes. "Local ownership of intangible assets located at the local level" (OWNERSH F2) shows a negative main effect if we do not take into account interaction effects, yet it turns out to be high, positive and significant if we are able to remove some of the interrelationships with other factors. "The use of formal means of sharing information" has a positive effect, but does not reach a level of significance. "The use of informal means of resource sharing across offices" has a consistent negative effect on performance.

We present the interpretation of certain interaction terms. We suggest that these interaction terms are significant. The parameter of AutoF3*ControlF3 (2.07) implies that for every unit that "lack of bureaucratic control" increases, the scope of "autonomy over the use of local resources" on performance increases with two units. In similar terms, the coefficient 1.93 of AUTOF3*ExpShINTP suggests that the scope of autonomy over the use of local resources on performance increases with almost two units, given a one unit increase in "independence and formal means of sharing expertise". However, we would have expected that the lack of operational control coupled with benefiting from operational autonomy would permit an office to tailor-make offerings of the firm to specific needs of local markets, and therefore be positively related to performance. Thus, the negative effect of AutoF4*Control F2 is counterintuitive.

\section{Cluster Analysis and Regression Analysis}

A cluster analysis was conducted in order to test which effect closeness to the business federation can have on performance. Our reasoning is that the more firms where involved in co-creation of services with clients, the more federated it would be. If it so that firms operating closer to principles of the federation achieve higher economic growth than firms operating further away from principles of the business federation, the organizational form can make sense for companies in our sample.

We attempted to control for other factors that can explain performance. We included origin (strategy practice or not), ownership structure (partnership or other organizational arrangements), the year the firm was founded, number of European consultants, number of strategy consultants at the local office, the age of the local offices, ownership structure, and the number of European consultants, as factors.

Since research on management consulting firms has not reached a very advanced level, it makes sense to conduct an inductive analysis. Through the use of K-means clustering we attempted to maximize within-cluster homogeneity relative to between-cluster heterogeneity. After initial cluster centroids are selected, each observation is assigned to the group with the nearest centroid. As each new observation is allocated, the cluster centroids were recomputed. To arrive at a reasonably good solution, passes were made through the dataset until no observations change clusters, 
leading us to conclude that the final solution optimizes within-cluster homogeneity and between-cluster heterogeneity. In order to meet these requirements the numbers of clusters were specified a priori.

The computer recommended four clusters, which is in accordance with our reasoning. The solution gives a strong degree of significance of the attributes for explaining federalist behavior. The value for operational autonomy was (0.059), autonomy in the relationship with other local offices was (0.077), cultural control scored 0.020 and the values for the rest of the attributes were 0.000 .

One cluster (cluster two) seems to operate close to federalist principles while another one seems to operate far removed from such principles (cluster four). The two other clusters can be described as behaving between these two clusters. In order to give the reader a better idea of the values of different clusters, see figure two where $\mathrm{C} 1, \mathrm{C} 2, \mathrm{C} 3$ and $\mathrm{C} 4$ represents the values of cluster one, two, three and four, respectively.

Insert Table 2 Here

\subsection{Performance within the Four Clusters}

We use profits per partner as the criteria to measure performance, using cluster two as the dummy variable. We suggest that cluster two operates closest to federalist principles. If this is the case, negative values of cluster one, three and four should be expected at significant statistical levels, making it possible to indicate that closeness to principles of the business federation has a positive effect on performance. When running a regression analysis we included the same demographic variables as we used in the factor analysis. Running a cluster analysis a R2 value of 0.87 and an adjusted R-square of 0.56 were achieved.

We also ran an analysis excluding control variables in order to get an indication of the importance of cluster membership. An R square of 0.438 was achieved, with an adjusted R square of 0.122 . This means that of an adjusted $\mathrm{R}$ square of 0.56 only 0.122 was explained by cluster membership.

Cluster two performs better than cluster four. However, since the levels of significance for cluster one and cluster three is low, it is not possible to conclude that cluster two performs better than cluster one and cluster three.

The findings support the argument that firms staring out from strategy achieve a stronger performance than other types of firms. Number of strategy consultants at the local level has a strong positive effect on performance. The research finds support for the argument that firms with a long experience score higher than firms with a shorter experience in the management consulting field.

\section{Discussion and Conclusion}

New patterns of competition threaten firm survival in virtually all industries. At the same time well-established management tools are no longer as relevant as they once were. We introduce the business federation as a new organizational form suited for firms facing dynamic and turbulent business environments. However, the conclusions provided can only be partial and preliminary as a result of a relatively small sample size.

A service-centered view identifies operant resources, especially higher-order core competences, as the key to obtaining competitive advantage (Vargo and Lusch, 2004). Ultimately, the most federated firms might be those whose core competence is marketing and all its related market-sensing processes (Day, 1999; Haeckel, 1999).

Historically, most communication with the market can be characterized as one-way, mass communication that flow from the offering firm to the market or to segments of markets. A service-centered view of exchange suggests that individual customers increasingly specialize and turn to their domesticated market relationships for services outside their own competences. The focus is shifting away from tangibles toward intangibles such as skills, information and knowledge, and toward ongoing relationships. Science has moved from a focus on mechanics on one on dynamic evolutionary development. Dialogue with customers becomes more important, where the objective is to ask and answer questions. Prahalad and Ramaswamy (2000) argue that customer rather than corporations are increasingly initiating and controlling this dialogue.

Using a bottom up perspective in order to tailor-make services, we argue that the days of mass-marketing are numbered. Today, firms are turning back to the competitive value of craftwork as an end in itself, where co creation becomes an important part of the service delivery process. Increasingly, companies succeed by offering tailored make services to carefully targeted market segments using crating as a method. Bottom-up organizations typically have an incredible appetite for experimentation with new ideas. Business renewal is at the center of the firm's attention as such a focus can lead to breakthrough performance.

Management consulting firms operate in dynamic and turbulent business environments. Change is driven by a myriad of socio-economic and technological factors that have influence on market trends and methods of satisfying customer needs. Management consulting firms need to achieve the benefits of adaptability and efficiency. Such 
firms seem to go further along the avenue to decentralization leading us to believe that certain companies can become federated. Our research suggests that large and older companies operating in multiple geographical locations within multiple businesses seem to be ahead of this emerging evolution. The business federation is not the only path. Some companies are retaining high degrees of centralization as they expand internationally, but we suggest that the trend is moving in the direction proposed in this study.

\section{References}

Bartlett, C. A., \& Ghoshal, S. (1988). Managing Across Borders: The Transnational Solution. Cambridge, Mass: Harvard Business School Press.

Bartlett, C. A., \& Ghoshal, S. (1995). Transnational Management: Text, Cases and Readings in Cross-Border Management (2nd ed.). Chicago: Irwin.

Constantin, J. A., \& Lusch, R. F. (1994). Understanding Resource Management. Oxford: The Planning Forum.

Day, G. (1994). The capabilities of market-driven organization. Journal of Marketing, 58, 37-52. http://dx.doi.org/10.2307/1251915

Day, G. (1999). The Market Driven Organization: Understanding, Attracting and Keeping Valuable Customers. New York: The Free Press.

Drucker, P. (1954). The Practice Management. New York: Harper and Row.

Ferlie, E., \& Pettigrew, A. M. (1996). Managing through networks: some issues and implications for the NHS. British Journal of Management, 7(S1), 81-99. http://dx.doi.org/10.1111/j.1467-8551.1996.tb00149.x

Grant, R. M (1996a). Propering in dynamically-competitive environments: organizational capability as knowledge integration. Organizational Science, 7(4), 375-387. http://dx.doi.org/10.1287/orsc.7.4.375

Grant, R. M (1996b). Towards a knowledge-based theory of the firm. Strategic Management Journal, 17(Winter Special Issue), 109-122.

Haeckel, S. H. (1999). Adaptive Enterprise: Creating and Leading Sense-and-Respond Organizations. Cambridge, Mass: Harvard School of Business.

Handy, C. (1994). The Age of Paradox, Cambridge, Mass: Harvard Business School Press.

Handy, C. (1992). Balancing corporate power: a new federalist paper. Harvard Business Review, 70(6), 59-72.

Leonard-Barton, D. (1995). Wellsprings of Knowledge: Building and Sustaining the Sources of Innovation. Boston, MA: Harvard Business School Press.

Lusch, R. F., Brown, S. W., \& Brunswick, G. J. (1992). A general framework for explaining internal vs. external exchange. Journal of the Academy of Marketing Science, 20(2), 119-134. http://dx.doi.org/10.1007/BF02723452

March, J. G., \& Simon, H. A. (1958). Organizations, New York: John-Wiley and Sons.

Nelson, R. R., \& Winter, S. G. (1982). An Evolutionary Theory of Economic Change. Cambridge, MA: Belknap Press.

Neu, W. A., \& Brown, S. W. (2008). Forming successful business-to-business services in goods-dominant forms. Journal of Service Research, 8(1), 3-17. http://dx.doi.org/10.1177/1094670505276619

Nonaka, I., \& Takeuchi, H. (1995). The Knowledge Creating Company, Oxford: Oxford University Press.

Normann, R., \& Ramírez, R. (1993). From value chain to value constellation: designing interactive strategy. Harvard Business Review, 71(4), 65-77.

Oliver, R., Roland, W., Rust, T., \& Varki, S. (1998). Real-time marketing. Marketing Management, 7(Fall), 28-37.

Prahalad, C. K., \& Ramaswamy, V. (2000). Co-opting customer competence. Harvard Business Review, 78(1), 79-87.

Provan, K. G. (1983). The federation as an interorganizational linkage network. Academy of Management Review, 1, 79-89. http://dx.doi.org/10.5465/AMR.1983.4287668

Sheh, J., Sisodia, R. S., \& Sharma, A. (2000). The antecedents and consequences of customer-centric marketing. Journal of the Academy of Marketing Science, 28 (1), 55-66. http://dx.doi.org/10.1177/0092070300281006

Shugan, S. M. (1994). Explanations for the Growth of Service. In R. T. Rust, and R. L. Oliver (Eds), Service Quality: New Directions in Theory and Practice (pp. 223-240). Thousand Oaks, CA: Sage Publications. 
Simon, H. A., Smith, A. J., \& Thompson, C. B. (1950). Modern organization theories. Advanced Management, 15, $2-14$.

Slater, S. F., \& Narver, J. C. (1995). Market orientation and the learning organization. Journal of Marketing, 59(3), 63-74. http://dx.doi.org/10.2307/1252120.

Teece, D., Pisano, G., \& Shuen, A. (1997). Dynamic capabilities and strategic management. Strategic Management Journal, 18 (7), 509-533. http://dx.doi.org/10.1002/(SICI)1097-0266(199708)18:7<509::AID-SMJ882>3.0.CO;2-Z.

Vargo, S. L., \& Lusch, R. F. (2004). Evolving to a new dominant logic for marketing. Journal of Marketing, 68(1), 1-17. http://dx.doi.org/10.1509/jmkg.68.1.1.24036.

Table 1. Regression Analysis (Factor Analysis)/Profit per Partner

\begin{tabular}{|c|c|}
\hline & Model \\
\hline \multicolumn{2}{|l|}{ Control Variables } \\
\hline 1 Cust. Intimacy Relations & $0.051^{* *}$ \\
\hline 2 Service Diversification & $0.264^{*}$ \\
\hline 3 Year Strategy Started & $0.034^{*}$ \\
\hline 4 Year Firm Found & $0.035^{* * *}$ \\
\hline 5 OwnershipStatus & $0.974^{*}$ \\
\hline 6 EuroConsultant & $0.444^{*}$ \\
\hline \multicolumn{2}{|l|}{ Explanatory variables } \\
\hline 7 AUTO F1 & $1.195^{* * *}$ \\
\hline 8 AUTO F2 & $0.604^{*}$ \\
\hline 9 AUTO F3 & -7.231 \\
\hline 10 AUTO F4 & $15.081^{* * *}$ \\
\hline 11 CONTROL F1 & 0.213 \\
\hline 12 CONTROL F2 & $6.369^{*}$ \\
\hline 13 CONTROL F3 & $4.090^{* *}$ \\
\hline 14 BOOSTING F1 & $0.347^{*}$ \\
\hline 15 BOOSTING F2 & -0.397 \\
\hline 16 OWNERSH F1 & -0.303 \\
\hline 17 OWNERSH F2 & $7.036^{* * *}$ \\
\hline 18 ResSharFormal F1 & 0.116 \\
\hline 19 ResSharInformal F2 & $-2.635^{* * *}$ \\
\hline 20 ExpShr-INTPD F3 ${ }^{* *}$ & $-6.073^{* *}$ \\
\hline \multicolumn{2}{|l|}{ Interaction terms } \\
\hline 21 AutoF3*ControlF2 & -1.345 \\
\hline 22 AutoF3*ControlF3 & $2.073^{* * *}$ \\
\hline 23 AutoF3*ExpShINTP & $1.930^{* * *}$ \\
\hline 24 AutoF4*Ownership2 & $-3.447^{* * *}$ \\
\hline 25 AutoF4*ControlF2 & $-1.405^{*}$ \\
\hline 26 AutoF4*ControlF3 & $-1.232^{* *}$ \\
\hline 27 Auto $4 *$ Ownsh $2 *$ Contr 2 & $0.377^{* * *}$ \\
\hline \multicolumn{2}{|l|}{ Intercept 5.035} \\
\hline R2 $\quad 0.901$ & \\
\hline \multicolumn{2}{|l|}{$\mathrm{F}=5.421$} \\
\hline Degrees of freedom 16 & \\
\hline
\end{tabular}

Note: ${ }^{*} \mathrm{p}<0.10 ;{ }^{* *} \mathrm{p}<0.05 ;{ }^{* * *} \mathrm{p}<0.01$. Based on 44 complete observations. 
Table 2. Results from a Cluster Analysis-Mean and Standard Deviations ( $\mathrm{C}=$ cluster, $\mathrm{SD}=$ standard deviation)

\begin{tabular}{|l|c|c|c|c|}
\hline & $\begin{array}{c}\mathrm{C} 1 \\
\text { Mean (SD) }\end{array}$ & $\begin{array}{c}\mathrm{C} 2 \\
\text { Mean (SD) }\end{array}$ & $\begin{array}{c}\mathrm{C} 3 \\
\text { Mean (SD) }\end{array}$ & $\begin{array}{c}\mathrm{C} 4 \\
\text { Mean (SD) }\end{array}$ \\
\hline Operational autonomy & $4.58(0.78)$ & $4.48(0.58)$ & $4.42(0.49)$ & $4.07(0.85)$ \\
\hline Autonomy-other local offices & $4.25(0.54)$ & $4.77(0.41)$ & $4.94(1.40)$ & $4.18(0.67)$ \\
\hline Cultural control & $5.48(0.60)$ & $5.90(0.87)$ & $1.43(0.48)$ & $5.50(0.73)$ \\
\hline Lack of operational control & $4.19(0.71)$ & $4.64(0.55)$ & $5.00(0.00)$ & $4.14(0.69)$ \\
\hline Payment and freedom to use support services & $4.13(1.54)$ & $6.18(1.21)$ & $4.83(0.41)$ & $3.32(1.22)$ \\
\hline Ownership over skills & $1.75(0.72)$ & $4.64(0.65)$ & $2.58(1.29)$ & $4.57(0.81)$ \\
\hline Formal means of interdependence & $4.08(0.51)$ & $3.88(0.62)$ & $3.75(1.37)$ & $3.86(0.62)$ \\
\hline
\end{tabular}

